\title{
ACERCA DE LA COMPETENCIA CONSULTIVA DEL TRIBUNAL PERMANENTE DE REVISION DEL MERCOSUR Y DE LA EXPERIENCIA DEL PODER JUDICIAL DEL URUGUAY EN LA TRAMITACIÓN DE OPINIONES CONSULTIVAS
}

SOBRE A COMPETÊNCIA CONSULTIVA DO TRIBUNAL PERMANENTE DE REVISÃO DO MERCOSUL E A EXPERIÊNCIA DO PODER JUDICIÂRIO DO URUGUAI NA TRAMITAÇÃO DE OPINIÔES CONSULTIVAS

Jorge Chediak González*

Pablo Benítez Rodríguez ${ }^{\star \star}$

Resumen: En el MERCOSUR no existe un Tribunal de Justicia, de allí la trascendencia de la labor que los órganos jurisdiccionales nacionales desarrollan, en la interpretación y aplicación del Derecho Comunitario en el orden interno. En esa labor juega un papel central la tarea consultiva conferida en el ámbito mercosuriano a su Tribunal Permanente de Revisión. La experiencia uruguaya en la tramitación de las opiniones consultivas, desde el año 2007 al 2012, ha sido de solamente dos solicitudes de Opinión Consultiva. El desafío actual lo constituye la adopción de políticas judiciales que incentiven a nuestros jueces a acudir a esta herramienta cuando tengan a su decisión un litigio en que resulte aplicable alguna norma del MERCOSUR.

Resumo: No MERCOSUL não existe um Tribunal de Justiça e essa característica estrutural dá transcendência ao trabalho desenvolvido pelos órgãos jurisdicionais nacionais na interpretação e na aplicação do Direito Comunitário na ordem jurídica interna. No cumprimento da referida missão, possui papel central a competência consultiva conferida pelo MERCOSUL ao seu Tribunal Permanente de Revisão. A experiência uruguaia na tramitação de opiniões consultivas, entre 2007 e 2012, contou

* Ministro de la Suprema Corte de Justicia de la República Oriental del Uruguay.

** Asistente Técnico Letrado de la Suprema Corte de Justicia de la República Oriental del Uruguay. 
com a solicitação de apenas duas opiniões consultivas. O desafio atual consiste na adoção de políticas judiciais que incentivem nossos juízes a recorrer a esta ferramenta quando tenham que decidir litígio, ao qual alguma norma do MERCOSUL se faça aplicável.

Palabras clave: Opiniones Consultivas, Protocolo de Olivos, Tribunal Permanente de Revisión

Palavras-chave: Opiniões Consultivas; Protocolo de Olivos; Tribunal Permanente de Revisão

\section{INTRODUCCION}

Sabido es que, a diferencia de otras experiencias de integración, dentro del MERCOSUR no existe un Tribunal de Justicia.

Como lo expresara el Dr. Mariano Brito: "No existe en el Tratado de Asunción ni en los consecuentes (Acuerdos y Protocolos) un órgano jurisdiccional habilitado para decir el derecho con fuerza de verdad legal $y$ autoridad de cosa juzgada. El sistema carece de un tribunal de justicia. Tampoco podría crearse por acto de los órganos del MERCOSUR, ya que atribuida su competencia a texto expreso, la facultad mencionada no se halla entre las suyas" (en "El Derecho de la Integración del MERCOSUR", Montevideo, 1999, págs. 164 y 165).

Por consecuencia de lo que viene de señalarse, la aplicación del derecho comunitario en el ámbito del Poder Judicial de los países integrantes del bloque se efectiviza a través de los jueces de cada Nación. De allí la trascendencia de la labor que los órganos jurisdiccionales nacionales desarrollan, dado que a éstos incumbe, en definitiva, la interpretación y aplicación del Derecho Comunitario en el orden interno.

Y es en esa labor de internalización del derecho comunitario que tienen a su cargo los jueces de cada país, que juega un papel central la tarea consultiva conferida en el ámbito mercosuriano a su Tribunal Permanente de Revisión, naturalmente, sin perjuicio de otras funciones asignadas a éste, que exceden el propósito de este trabajo.

\section{EL TRIBUNAL PERMANENTE DE REVISIÓN DEL MERCOSUR, Y SU FUNCIÓN CONSULTIVA A SOLICITUD DE LOS TRIBUNALES SUPERIORES DE JUSTICIA}

Sabido es que en todo proceso de integración entre Estados resulta necesaria la presencia de mecanismos que tengan por función la solución de las diferencias o contiendas que naturalmente se suscitan en el desenvolvimiento del proceso integrador. 
Seguramente reconociendo esa realidad, el MERCOSUR desde su origen previó mecanismos de solución de controversias. Ello se refleja en el Tratado de Asunción de 1991 (que en su artículo 3 establece: “... y a fin de facilitar la constitución del Mercado Común, los Estados Partes adoptan un Régimen General de Origen, un Sistema de Solución de Controversias y Cláusulas de Salvaguardia"), Protocolo de Brasilia de 1991 (artículo 1 y siguientes), Protocolo de Ouro Preto de 1994 (particularmente, artículo 43), y finalmente, Protocolo de Olivos celebrado el 18 de febrero de 2002 que institucionaliza el régimen vigente desde el $1^{\circ}$ de enero de 2004, creando el Tribunal Permanente de Revisión. "Este instrumento presenta dos grandes características: por un lado atiende a controversias entre Estados y entre Estados y particulares; y por otro lado fija procedimientos, con mecanismos políticos y mecanismos jurisdiccionales, a través de un régimen arbitral sui generis en base a tribunales arbitrales ad hoc y el TPR como órgano superior" (Dr. Roberto Puceiro Ripoll en “iTPR! Tribunal Permanente de Revisión del MERCOSUR").

La función consultiva fue conferida al Tribunal Permanente de Revisión del MERCOSUR por el artículo 3 Protocolo de Olivos, donde se dispuso: "El Consejo del Mercado Común podrá establecer mecanismos relativos a la solicitud de opiniones consultivas al Tribunal Permanente de Revisión definiendo su alcance y sus procedimientos". Luego, por medio del Reglamento de dicho instrumento, se desarrolló el concepto regulando los diversos aspectos que hacen a su funcionamiento.

La composición del Tribunal fue prevista en el artículo 18 del Protocolo de Olivos, el cual estableció:

"1. El Tribunal Permanente de Revisión estará integrado por cinco (5) árbitros.

2. Cada Estado Parte del MERCOSUR designará un (1) árbitro y su suplente por un período de dos (2) años, renovable por no más de dos períodos consecutivos.

3. El quinto árbitro, que será designado por un período de tres (3) años no renovable salvo acuerdo en contrario de los Estados Partes, será elegido por unanimidad de los Estados Partes, de la lista a que hace referencia este numeral, por lo menos tres (3) meses antes de la expiración del mandato del quinto árbitro en ejercicio. Dicho árbitro tendrá la nacionalidad de alguno de los Estados Partes del MERCOSUR. Todo ello sin perjuicio de lo dispuesto en el numeral 4 de este artículo.

No lográndose unanimidad, la designación se hará por sorteo que realizará la Secretaría Administrativa del MERCOSUR entre los integrantes de esa lista, dentro de los dos (2) días siguientes al vencimiento de dicho plazo.

La lista para la designación del quinto árbitro se conformará con ocho (8) integrantes. Cada Estado Parte propondrá dos (2) integrantes que deberán ser nacionales de los países del MERCOSUR. 
4. Los Estados Partes, de común acuerdo, podrán definir otros criterios para la designación del quinto árbitro.

5. Por lo menos tres (3) meses antes del término del mandato de los árbitros, los Estados Partes deberán manifestarse respecto de su renovación o proponer nuevos candidatos.

6. En caso de que expire el período de actuación de un árbitro que se encuentra entendiendo en una controversia, éste deberá permanecer en funciones hasta su conclusión.

7. Se aplicará, en lo pertinente, a los procedimientos descriptos en este artículo lo dispuesto en el artículo 11.2.".

Conforme lo establece el artículo 6.1 del Reglamento, para emitir opiniones consultivas el Tribunal Permanente de Revisión deberá integrarse con todos sus miembros.

Del artículo 2 del Reglamento del Protocolo de Olivos para la Solución de Controversias (en adelante "Reglamento") surge que la legitimación activa en materia consultiva frente al Tribunal Permanente de Revisión corresponde a todos los Estados Partes del MERCOSUR actuando conjuntamente, los órganos con capacidad decisoria del MERCOSUR y los Tribunales Superiores de los Estados Partes con jurisdicción nacional, en las condiciones que se establecen para cada caso. Surge pues que el ejercicio de la competencia consultiva supone siempre la actuación de los entes públicos señalados por la norma referida, no previéndose la posibilidad de la actuación del Tribunal por solicitud directa de particulares. Claro que éstos como, partes de un juicio, podrán solicitar al juez de la causa se recabe la opinión del Tribunal Permanente del Revisión.

En cuanto a la materia u objeto de la consulta la misma podrá versar sobre cualquier cuestión jurídica comprendida en el Tratado de Asunción, el Protocolo de Ouro Preto, los protocolos y acuerdos celebrados en el marco del Tratado de Asunción, las Decisiones del Consejo Mercado Común, las Resoluciones del Grupo Mercado Común y las Directivas de la Comisión de Comercio del MERCOSUR. Como puede verse, la función consultiva asignada al Tribunal Permanente de Revisión es eminentemente jurídica y su ejercicio no encierra la resolución de causa particular alguna.

En lo relativo a las opiniones consultivas provenientes de los Tribunales Superiores de Justicia de los Estados, el artículo 4 del Reglamento establece que el objeto de la consulta podrá versar exclusivamente sobre la interpretación jurídica de la normativa del MERCOSUR mencionada en el párrafo precedente. En la parte final de dicho artículo se dispone que las opiniones consultivas requeridas deberán vincularse "con causas que estén bajo trámite en el Poder Judicial del Estado Parte solicitante", lo que permite incluir en la materia no solo una inquietud propia del órgano máximo del Poder Judicial involucrado, 
sino que también las provenientes de todos los órganos jurisdiccionales inferiores. En tal medida, la opinión consultiva se constituye en un elemento de cooperación judicial de suma importancia, al alcance de todos los jueces de los países del bloque.

En lo que dice relación con las formalidades de la presentación, el artículo 5 del Reglamento dispone que la solicitud deberá plantearse por escrito, formulando en términos precisos la cuestión respecto de la cual se realiza la consulta y las razones que la motivan, indicando las normas del MERCOSUR vinculadas a la petición. Asimismo deberá acompañarse, si correspondiere, toda la documentación que pueda contribuir a su dilucidación.

Originalmente, el Tribunal contaba con un plazo de cuarenta y cinco días para expedirse (cfme. texto original del artículo 7 del Reglamento), pero dicho plazo fue extendido a sesenta y cinco días corridos contados a partir de la recepción de la solicitud de la Opinión Consultiva (artículo 1 de la Decisión No 15/10, del 2/VIII/2010). De regla, dicho plazo no se suspenderá, salvo que "lo considere necesario" el Tribunal a fin de solicitar a los peticionantes de la opinión consultiva aclaraciones o documentación que estime pertinentes (artículo 8 del Reglamento).

Respecto de su contenido, el artículo 9 del Reglamento dispone que las opiniones consultivas deberán ser fundadas, particularmente en la normativa mencionada en el artículo 34 del Protocolo de Olivos, suscritas por todos los árbitros intervinientes y expresando: a) una relación de las cuestiones sometidas a consulta; b) un resumen de las aclaraciones de los solicitantes, si el Tribunal las hubiese pedido; y c) el dictamen del Tribunal Permanente de Revisión con la opinión de la mayoría y las opiniones en disidencia, si las hubiera.

El procedimiento podrá concluir por la emisión de la opinión consultiva requerida, la comunicación al peticionante de que las opiniones consultivas no serán emitidas por alguna causa fundada, tal como la carencia de los elementos necesarios para el pronunciamiento del Tribunal Permanente de Revisión y por el inicio de un procedimiento de solución de controversias sobre la misma cuestión, en este caso “... el procedimiento consultivo deberá ser finalizado por el TPR sin más trámite" (artículo 10 del Reglamento).

Finalmente, en cuanto a sus efectos, las opiniones consultivas emitidas por el Tribunal Permanente de Revisión no son vinculantes ni obligatorias para quien la peticionó (artículo 11 del Reglamento). Ello es particularmente relevante en el entendido de que si la opinión consultiva fue movilizada por un Tribunal Superior de Justicia de un Estado Parte su solicitud tendrá origen en un litigio sometido a su decisión o la de un Tribunal inferior de su país y, en cualquiera de las hipótesis, los jueces nacionales no se verán obligados a seguir en sus fallos los lineamientos 
emergentes de la opinión consultiva.

Lo que viene de expresarse, lo es sin desconocer que dichas manifestaciones del Tribunal Permanente de Revisión, sin ser vinculantes, tienen particular autoridad como enunciados jurídicos emanados de un órgano especializado en la temática de su materia, por lo que el apartamiento de sus enunciados requerirá del Juez de la causa un especial y fundado pronunciamiento.

\section{EN CUANTO A LA EXPERIENCIA EN LA TRAMITACIÓN EN LA OPINIÓN CONSULTIVA POR LOS TRIBUNALES DE LA REPÚBLICA ORIENTAL DEL URUGUAY}

Entrando a la experiencia en la tramitación de la Opinión Consultiva en Uruguay, como lo indica el artículo 4 del Reglamento del Protocolo de Olivos, las originadas en procesos judiciales son tramitadas a través de la Suprema Corte de Justicia, en su carácter de Tribunal Superior de Justicia de la República. Por tratarse de un gobierno unitario, no se presentan en mi país los problemas que se han planteado en los casos de Argentina y Brasil que tienen un sistema federal de gobierno.

Por Decisión $N^{\circ}$ 2/2007 del Consejo del Mercado Común se dispuso que cada Tribunal Superior de Justicia de los Estados Partes, en el ámbito de sus respectivas jurisdicciones, establecerá las reglas internas de procedimiento para la solicitud de opiniones consultivas, verificando la adecuación procesal de la solicitud.

En razón de ello, la Suprema Corte de Justicia de Uruguay ha dictado la Acordada No 7.604, del 24/08/2007 (comunicada por Circular No 86/2007), que a continuación me permito transcribir parcialmente:

"10.- Si en una causa en trámite ante cualquier órgano del Poder Judicial se suscitare una duda acerca de la validez o interpretación jurídica de la siguiente normativa del Mercosur: el Tratado de Asunción, el Protocolo de Ouro Preto, los protocolos y acuerdos celebrados en el marco del Tratado de Asunción, las Decisiones del Consejo del Mercado Común (CMC), las Resoluciones del Grupo Mercado Común (GMC) y las Directivas de la Comisión de Comercio del Mercosur (CCM), dicho órgano podrá requerir una opinión consultiva al Tribunal Permanente de Revisión del Mercosur (TPR) (Arts. 3 y 4 de la decisión del CMC No. 37/03, Reglamento del Protocolo de Olivos).

$2^{\circ}$.- A tales efectos, el órgano del Poder Judicial en cuya jurisdicción resida el conflicto, deberá elevar a la Suprema Corte de Justicia la solicitud de opinión consultiva.

La solicitud deberá realizarse por escrito, formulándose en términos precisos la cuestión respecto de la cual se realiza la consulta de interpretación jurídica de la normativa del Mercosur y las razones que la motivan, indicando concretamente la normativa a interpretar $e$ 
incluyendo una precisa reseña de las cuestiones de hecho planteadas.

Deberá acompañarse -si correspondiere- toda la documentación $y$ antecedentes que puedan contribuir a su dilucidación, o en su caso testimonio de los mismos (Art. 5 de la decisión del CMC No. 37/03, Reglamento del Protocolo de Olivos).

$3^{\circ}$.- La Suprema Corte de Justicia deberá verificar que en el caso se configuren los siguientes requisitos de admisibilidad:

a) Que las opiniones consultivas solicitadas refieran exclusivamente a la interpretación o validez jurídica de la normativa citada en forma taxativa.

b) Que las opiniones consultivas que se soliciten estén vinculadas con causas que estén bajo trámite en el Poder Judicial.

c) Que la opinión consultiva que se solicite verse sobre normativa cuya interpretación o validez no fuera manifiestamente clara.

d) Que el tema objeto de la consulta no haya sido materia de una previa opinión consultiva, en cuyo caso se agregará testimonio de ésta y se devolverá a la sede judicial de origen con noticia de las partes.

$4^{\circ}$.- En caso de cumplir con los requisitos antes señalados, la Suprema Corte de Justicia remitirá directamente al Tribunal Permanente de Revisión (TPR) las solicitudes de opiniones consultivas, adjuntando todos los antecedentes y documentación correspondientes (o en su caso su testimonio o copia fotostática), el que se expedirá por escrito y dispondrá para ello de cuarenta y cinco días contados a partir de la recepción de la solicitud de la opinión consultiva (Art. 7 de la decisión del CMC No. 37/03, Reglamento del Protocolo de Olivos), sin perjuicio de lo dispuesto en el Art. 12 b del citado Reglamento.

50.- Las decisiones del TPR emitidas en la solicitud de opiniones consultivas objeto de la presente Acordada serán comunicadas directamente a la Suprema Corte de Justicia (sin perjuicio de las notificaciones a los Estados Partes dispuestas por el Art. $10 \mathrm{Nal}$. 2 del Reglamento del Protocolo de Olivos aprobado por Decisión del CMC No. 37/03), la que las comunicará a su vez a los órganos del Poder Judicial que las hubieren requerido.

$6^{\circ}$.- Efectos de la opinión consultiva:

La opinión consultiva emitidapor el TPR será referida exclusivamente a la validez o a la interpretación jurídica de la normativa del Mercosur mencionada a texto expreso y no tendrá carácter vinculante ni obligatorio (Art. 11 de la decisión del CMC No. 37/03), y ello en tanto tales opiniones no pueden afectar en absoluto el derecho interno ni las potestades del Poder Judicial.

$7^{\circ}$.- A todos los efectos, incluso los previstos en el Art. $3^{\circ}$, en la Suprema Corte de Justicia se llevará un registro al que se incorporarán los textos de las consultas evacuadas por el TPR, antes de su remisión al tribunal de origen. 
$8^{\circ}$.- Una vez evacuada la consulta por el TPR, la Suprema Corte de Justicia la remitirá al tribunal de origen a efectos de que éste continúe con los procedimientos.".

Surge de lo transcripto que la Suprema Corte de Justicia de Uruguay ha reglamentado, minuciosamente, el trámite a seguir para la presentación de la opinión consultiva originada en un proceso judicial, en consonancia con los lineamientos dados por la norma comunitaria, particularmente lo establecido en el Reglamento del Protocolo de Olivos para la Solución de Controversias en el Mercosur.

Entrando a lo que ha sido la experiencia uruguaya en la tramitación de las opiniones consultivas, debo señalar que desde el año 2007 al 2012, la Suprema Corte de Justicia ha gestionado solamente dos solicitudes de Opinión Consultiva, a saber:

- "Juzgado Letrado de Primera Instancia en lo Civil de 1er. Turno, en autos: 'Sucesión Carlos Schneck y otros c/ Ministerio de Economía y Finanzas y otros - Cobro de Pesos' Ficha: 2 - 32247/2007”. El trámite fue iniciado el día 28 de julio de 2008 y luego de los trámites de estilo, el Tribunal Permanente de Revisión se expidió mediante Opinión Consultiva No $1 / 2008$.-

- "Juzgado Letrado de Primera Instancia en lo Civil de 2o Turno, en autos: 'Frigorífico Centenario S.A. c/ Ministerio de Economía y Finanzas y otros - Cobro de Pesos' Ficha: 2 - 43923/2007”. El trámite fue iniciado el día 24 de octubre de 2008 y luego de los trámites de rigor, el Tribunal Permanente de Revisión se expidió mediante Opinión Consultiva No $1 / 2009$.-

Surge del relevamiento que viene de efectuase, que al día de hoy la opinión consultiva no constituye en mi país una herramienta a la cual recurran los operadores del Derecho (partes y juez) con habitualidad.

Siendo esta la realidad, teniendo presente el valor que la opiniones consultivas tienen como instrumento para comprensión y aplicación uniforme del derecho comunitario por los jueces de los Estados Parte y lo que ello significa como contribución a una real integración regional, el desafío actual lo constituye la adopción de políticas judiciales que incentiven a nuestros jueces a acudir a esta herramienta cuando tengan a su decisión un litigio en que resulte aplicable alguna norma emanada de los órganos del MERCOSUR, pues en definitiva, como se ha señalado por prestigiosa doctrina, la opinión consultiva constituye la principal herramienta de cooperación entre el juez nacional y la jurisdicción supranacional en el ámbito del bloque regional (Cfme. Perotti, Alejandro, Tribunal Permanente de Revisión y Estado de Derecho en el Mercosur, Konrad Adenauer Stiftung, Editorial Marcial Pons, Buenos Aires, 2008"). 


\section{REFERENCIAS BIBLIOGRÁFICAS}

BRITO Mariano (1999) El Derecho de la Integración del MERCOSUR. Montevideo: UDELAR.

CASO 'Frigorífico Centenario S.A. c/ Ministerio de Economía y Finanzas y otros - Cobro de Pesos' Ficha: 2 - 43923/2007.

CASO 'Sucesión Carlos Schneck y otros c/ Ministerio de Economía y Finanzas y otros - Cobro de Pesos' Ficha: 2 - 32247/2007.

PUCEIRO RIPOLL Roberto “'TPR! Tribunal Permanente de Revisión del MERCOSUR”. [online] <http://www.fder.edu.uy/contenido/rrii/ temas.html>.

PEROTTI Alejandro (2008) Tribunal Permanente de Revisión y Estado de Derecho en el Mercosur. Buenos Aires: Konrad Adenauer Stiftung y Editorial Marcial Pons. 